\section{Phytophthora Fruit Rot-resistant Watermelon Germplasm Lines USVL489-PFR, USVL782-PFR, USVL203-PFR, and USVL020-PFR}

\author{
Chandrasekar S. Kousik ${ }^{\mathbf{1}}$ and Kai-Shu Ling \\ U.S. Department of Agriculture-Agricultural Research Service, U.S. Vegetable \\ Laboratory, 2700 Savannah Highway, Charleston, SC 29414
}

\section{Scott Adkins, Craig G. Webster, and William W. Turechek \\ U.S. Department of Agriculture-Agricultural Research Service, U.S. Horticultural Research Laboratory, Ft. Pierce, FL 34945}

Additional index words. Citrullus, egusi, oomycete, Phytophthora capsici, Phytophthora fruit rot, resistance

USVL489-PFR, USVL782-PFR, USVL203PFR, and USVL020-PFR are watermelon [Citrullus lanatus var. lanatus (Thunb.) Matsum. \& Nakai] germplasm lines that exhibit high levels of resistance to Phytophthora fruit rot caused by the plant pathogen Phytophthora capsici. Resistance in these germplasm lines is expressed as significantly reduced to practically no lesion development, rot, or pathogen sporulation on the fruit compared with large lesions, severe rot, and heavy sporulation on commercial watermelon cultivars Sugar Baby, Black Diamond, and Mickey Lee. These four USVL germplasm lines are each highly uniform for growth characteristics, fruit size, shape, and color. Currently commercial watermelon cultivars with resistance to Phytophthora fruit rot are not available. These four USVL germplasm lines may be a useful source for incorporating resistance in commercially acceptable watermelon cultivars.

\section{Origin}

Each of these germplasm lines is derived from materials in the U.S. PI watermelon

\footnotetext{
Received for publication 23 Sept. 2013. Accepted for publication 31 Oct. 2013.

This research was supported in part by funding from Cucurbit Corp Germplasm Committee (CGC) of the USDA.

Mention of a trademark name or proprietary product does not constitute a guarantee or warranty of the product by the U.S. Department of Agriculture, Agricultural Research Service (USDA, ARS) nor does it imply exclusion of other products that may also be suitable.

We acknowledge the technical assistance of Jennifer Ikerd, Danny Cook, Richard Carrington, Kim Alford, Stephanie Berry, Mira Patel, Carrie Vanderspool, Steve Mayo, and Paul Cossman in conducting many of these experiments. Critical review of the manuscript by Drs. Mike Jackson and Howard Harrison is also appreciated.

${ }^{1}$ To whom reprint requests should be addressed; e-mail shaker.kousik@ars.usda.gov.
}

core collection maintained at the USDA, ARS, Plant Genetic Resources and Conservation unit (PGRCU), Griffin, GA. These four accessions were originally collected in Nigeria and classified as Citrullus lanatus var. lanatus. USVL489-PFR, USVL782-PFR, USVL203-PFR, and USVL020-PFR were derived from PI 186489, PI 306782, PI 595203, and PI 560020, respectively. Although PI 595203 was developed as a line with virus resistance in Georgia and deposited in the germplasm collection, the original source used to develop PI 595203 was collected in Nigeria based on the records maintained by GRIN (<http://www.ars-

\section{Disease Resistance}

Phytophthora fruit rot of watermelon, caused by Phytophthora capsici, was first reported in 1940 (Wiant and Tucker, 1940) and is prevalent in many watermelongrowing regions of the United States (Gevens et al., 2008; Granke et al., 2012; Hausbeck and Lamour, 2004; Kousik et al., 2011; McGrath, 1996). The disease is particularly severe in the southeastern United States where optimal conditions for development of the disease are prevalent. Between 2003 and 2008, many watermelon farms in Georgia, South Carolina, and North Carolina did not harvest a crop as a result of severe fruit rot. In some instances fruits rotted after shipping, resulting in rejection of entire loads and loss of revenue (Jester and Holmes, 2003; Kousik et al., 2011). Similarly, in 2013, watermelon growers in Georgia and North Carolina lost their crop to pre- and postharvest fruit rot. Such occurrences have led the U.S. National Watermelon Association to list Phytophthora fruit rot as a top research priority (Morrissey, 2006; Morrissey, personal communication). Because fruit rot has become a major problem in watermelon, developing sources of resistance for breeding into resistant commercial cultivars is considered important. grin.gov>)
In the original screens of the core collection and a collection of select PIs conducted in 2009 and 2010, respectively, fruit harvested from individual plants within a PI exhibited varying levels of resistance (Kousik et al., 2012). Therefore, a pure line selection procedure was adopted to develop highly resistant homogenous individuals for use in breeding programs. The process of developing resistant lines began in a greenhouse with self-pollination of individual plants of each of these four PIs. Fruit from individual plants were screened with a highly virulent South Carolina isolate of Phytophthora capsici. Each fruit was inoculated with a 7-mm agar plug from an actively growing colony of $P$. capsici on V8 juice agar and placed in a walk-in humidity chamber (greater than $95 \%$ relative humidity, temperature $26 \pm 2{ }^{\circ} \mathrm{C}$ ). Fruit of susceptible commercial cultivars Black Diamond, Sugar Baby, and PI 536464 grown similarly were included as controls during the selection process. Data on lesion development and sporulation were recorded $5 \mathrm{~d}$ after fruit inoculations when large lesions and heavy sporulation were noticed on fruit of susceptible cultivars. Seeds from highly resistant individuals were selected and plants were grown and screened further. During each selection cycle, seeds from two to four highly resistant individual plants were planted for the next generation. In total, we screened and selected individual plants from each PI for five successive generations using a pure line selection procedure to develop $\mathrm{S}_{5}$ lines designated as USVL489-PFR, USVL782-PFR, USVL203PFR, and USVL020-PFR. Lesions on inoculated fruit of USVL489-PFR, USVL782-PFR, USVL203-PFR, and USVL020-PFR were barely noticeable around the inoculum plug and were generally less than $1 \mathrm{~cm}$ in diameter (range, 0 to $2 \mathrm{~cm}$ in diameter) compared with 'Sugar Baby', where the fruit rot lesions were large ranging from 9 to $13 \mathrm{~cm}$ in diameter and covered $\approx 80 \%$ (range, $55 \%$ to $100 \%$ ) of the fruit's top visible surface. Similarly, on the susceptible cultivar Black Diamond, the lesions were 5 to $19 \mathrm{~cm}$ in diameter and covered greater than $50 \%$ of the fruit's top surface. PI 536464 was highly susceptible in these tests and in most instances the fruit completely rotted and collapsed within $4 \mathrm{~d}$ after inoculation. Lesion diameter on PI 536464 ranged from 9 to $18 \mathrm{~cm}$. No pathogen sporulation occurred on inoculated fruit of USVL489PFR, USVL782-PFR, USVL203-PFR, and USVL020-PFR, whereas heavy sporulation was observed on 'Black Diamond', 'Sugar Baby', and PI 536464 and the mean sporulation intensity was generally greater than 4 on a 0 to 5 scale described previously (Kousik et al., 2012; $0=$ no sporulation and $5=$ greater than $85 \%$ lesion area covered with heavy pathogen growth and sporulation). The advanced germplasm lines were evaluated in three field trials in 2012 (summer and fall) and 2013 (summer) to confirm their resistance. Each USVL germplasm line was evaluated in four replicated plots with five 
plants per replication spaced $46 \mathrm{~cm}$ apart. Plot-to-plot spacing was $2.3 \mathrm{~m}$. Harvested fruit were inoculated and data on fruit rot was recorded as described before (Kousik et al., 2012). All fruit rot data were analyzed in an analysis of variance using the SAS procedure PROC GLM (SAS Institute Inc., Cary, NC) and means were separated using Fisher's protected least significant difference $(\alpha=0.05)$. All four USVL lines were highly resistant to Phytophthora fruit rot compared with susceptible controls (Table 1; Fig. 1).

The fruit rind and flesh below the inoculated area and around the plug of the four resistant germplasm lines remained firm even after being in the humidity chamber for more than $6 \mathrm{~d}$ after inoculation, thus confirming their resistance. In some instances, a dark lesion below the $P$. capsici agar plug was formed on some of the fruit. This lesion generally did not extend beyond $1 \mathrm{~cm}$ in diameter. On susceptible cultivars, fruit rot also extended within the fruit compared with limited growth to no visible symptoms within the resistant germplasm lines (Fig. 2). In our previous studies, significantly lower amounts of the pathogen ( $P$. capsici) DNA were detected by real-time quantitative polymerase chain reaction in the fruit tissue of the resistant lines compared with fruit of 'Black Diamond' or PI 536464, further confirming resistance to Phytophthora fruit rot (Kousik et al., 2012).

All four germplasm lines can be easily crossed with commercial cultivated-type watermelon to produce $F_{1}$ and $F_{2}$ seeds for breeding purposes. We are currently conducting inheritance studies to determine the genetics of resistance and develop inbred lines with red flesh and fruit rot resistance for use in breeding programs.

Phytophthora capsici is a highly variable pathogen in terms of virulence on fruit (Granke et al., 2011; Quesada-Ocampo et al., 2010). Furthermore, the potential for existence of races of $P$. capsici (Glosier et al., 2008; Granke et al., 2011) has also been reported. Therefore, even when commercial watermelon varieties with resistance are developed using these four germplasm lines as resistance sources, an integrated disease management strategy including the use of appropriate cultural practices and fungicides should be used to manage Phytophthora fruit rot.

Characteristics of USVL489-PFR. USVL489-PFR was derived from PI 186489, the seeds of which were originally collected in 1949 from a local market in Ijoko, Nigeria, and deposited with PGRCU in 1950. USVL489-PFR has a runner growth habit with lobed leaves $(15.8 \times 16.0 \mathrm{~cm})$. The line is monoecious with each plant producing five to six small almost round fruits $(11.9 \times$ $11.8 \mathrm{~cm}$ ). Fruit color is medium dark green with slightly darker green stripes. The color of the fruit rind determined using a Konica Minolta Chroma Meter (CR-400 with 8-mm aperture and $2^{\circ}$ viewing angle) and the CIE $\mathrm{L}^{*} \mathrm{a} \mathrm{b}^{*}$ color data software (CM-S100w SpectraMagic NX, Version 1.7; Konica Minolta) is medium-dark green with mean color coordinate readings of $\mathrm{L}^{*}=49.9$,

Table 1. Comparison of Phytophthora fruit rot development on four USVL fruit rot-resistant watermelon germplasm lines and commercial cultivars over three trials conducted in Charleston, SC.

\begin{tabular}{|c|c|c|c|}
\hline $\begin{array}{l}\text { USVL germplasm } \\
\text { line/cultivar }\end{array}$ & $\begin{array}{l}\text { Lesion diam } \\
(\mathrm{cm})^{\mathrm{z}}\end{array}$ & $\begin{array}{c}\text { Growth/sporulation } \\
(\mathrm{cm})^{\mathrm{y}}\end{array}$ & $\begin{array}{l}\text { Sporulation intensity } \\
\qquad(0-5)^{\mathrm{x}}\end{array}$ \\
\hline \multicolumn{4}{|l|}{2012 Summer } \\
\hline USVL489-PFR & 1.3 & 0.2 & 0.1 \\
\hline USVL782-PFR & 1.6 & 0.7 & 0.4 \\
\hline USVL203-PFR & 1.1 & 0.0 & 0.0 \\
\hline USVL020-PFR & 0.8 & 0.0 & 0.0 \\
\hline Sugar Baby & 10.4 & 9.5 & 5.0 \\
\hline Mickey Lee & 10.2 & 8.6 & 4.8 \\
\hline Crimson Sweet & 9.5 & 6.5 & 4.0 \\
\hline $\mathrm{LSD}_{0.05}$ & 1.7 & 1.8 & 0.6 \\
\hline \multicolumn{4}{|l|}{2012 Fall } \\
\hline USVL489-PFR & 0.6 & 0.2 & 0.2 \\
\hline USVL 782-PFR & 0.7 & 0.3 & 0.2 \\
\hline USVL203-PFR & 1.2 & 0.3 & 0.1 \\
\hline USVL020-PFR & 1.0 & 0.5 & 0.4 \\
\hline Black Diamond & 9.2 & 9.2 & 4.4 \\
\hline $\mathrm{LSD}_{0.05}$ & 2.0 & 1.8 & 1.1 \\
\hline \multicolumn{4}{|l|}{2013 Summer } \\
\hline USVL489-PFR & 0.7 & 0.4 & 0.2 \\
\hline USVL 782-PFR & 1.1 & 0.4 & 0.4 \\
\hline USVL203-PFR & 0.8 & 0.0 & 0.0 \\
\hline USVL020-PFR & 0.4 & 0.0 & 0.0 \\
\hline Sugar Baby & 12.4 & 11.8 & 4.8 \\
\hline Mickey Lee & 11.3 & 10.8 & 4.6 \\
\hline $\mathrm{LSD}_{0.05}$ & 1.2 & 1.4 & 0.5 \\
\hline
\end{tabular}

${ }^{\mathrm{z}}$ The lesion diameter was recorded on the surface of the fruit that appeared water-soaked.

yPathogen growth and sporulation diameter was the area within the water soaked lesion covered with sporangia and visible pathogen growth as shown in Fig. 1.

${ }^{x}$ Sporulation intensity was the amount of visible sporulation on the fruit surface rated on a 0 to 5 scale $(0=$ no sporulation and $5=$ heavy sporulation covering greater than $80 \%$ of the lesion area; Kousik et al., 2012). LSD $=$ least significant difference. $\mathrm{a}^{*}=-16.1$, and $\mathrm{b}^{*}=26.2$. The darker green stripes on the rind had mean color coordinate readings of $\mathrm{L}^{*}=42.02$, a* $=$ -14.1 , and $b^{*}=20.7$. Fruit flesh is very firm and white-colored with mediumsized tan-colored egusi-type seeds. Each fruit generally weighed less than $1 \mathrm{~kg}$ (average, $0.87 \mathrm{~kg}$ ) with the range being 0.64 to $1.25 \mathrm{~kg}$ in field tests conducted at Charleston, SC, and Fort Pierce, FL. The Brix value for mature fruit is very low and ranges from less than 2 to 4 . The fruit of USVL489PFR are highly resistant to fruit rot compared with commercial watermelon varieties based on trials conducted in 2012 and 2013 (Table 1; Fig. 1).

Characteristics of USVL782-PFR. USVL782-PFR was derived from PI 306782, the seeds of which were originally collected from a local market in Oyo, Nigeria, before 1965 and deposited with PGRCU in 1965. USVL782-PFR has a runner growth habit with deeply lobed leaves $(18.0 \times 16.5 \mathrm{~cm})$. The line is monoecious with each plant producing three to four almost round fruits $(11.8 \times 12.3 \mathrm{~cm})$. Fruit rind color is normal green $\left(\mathrm{L}^{*}=47.4\right.$, $\mathrm{a}^{*}=-18.1$, and $\left.\mathrm{b}^{*}=28.6\right)$ with slightly darker green stripes $\left(\mathrm{L}^{*}=36.4, \mathrm{a}^{*}=-13.2\right.$, and $\mathrm{b}^{*}=$ 16.1). Fruit flesh is very firm and whitecolored with medium-sized white-colored egusi-type seeds. Each fruit generally weighs less than $1 \mathrm{~kg}$ (average, $0.91 \mathrm{~kg}$ ) with the range being 0.64 to $1.52 \mathrm{~kg}$ in field tests conducted at Charleston, SC, and Fort Pierce FL. The Brix value for mature fruit is very low and ranges from 1 to 3 . The fruit of USVL782PFR are highly resistant to fruit rot compared with commercial watermelon varieties based on trials conducted in 2012 and 2013 (Table 1; Fig. 1).

Characteristics of USVL203-PFR. USVL203-PFR was derived from PI 595203, the seeds of which were donated to PGRCU in 1990, from Alabama. USVL203-PFR has a runner growth habit with lobed leaves $(16.5 \times 16.7 \mathrm{~cm})$. Each plant produces almost round fruits $(12.9 \times 13.3 \mathrm{~cm})$. Fruit rind color is light green $\left(\mathrm{L}^{*}=66.1, \mathrm{a}^{*}=-13.7\right.$, and $\mathrm{b}^{*}=$ 27.2). Fruit flesh is very firm and whitecolored with medium-sized white- to creamcolored egusi-type seeds. Each fruit generally weighs $\approx 1 \mathrm{~kg}$ (average, $1.2 \mathrm{~kg}$ ) in field tests conducted at Charleston, SC. The Brix value for mature fruit is very low and ranges from 1.6 to 2.5. The fruit of USVL203-PFR are highly resistant to fruit rot compared with commercial watermelon varieties based on trials conducted in 2012 and 2013 (Table 1; Fig. 1).

Characteristics of USVL020-PFR. USVL020-PFR was derived from PI 560020, the seeds of which were originally collected in Oyo, Nigeria, in 1984 and donated to PGRCU in 1990. USVL020-PFR has a runner growth habit with lobed leaves $(16.9 \times$ $17.1 \mathrm{~cm})$. The line is monoecious with each plant producing four to five almost round fruits $(12.3 \times 12.5 \mathrm{~cm})$. Fruit color is normal green $\left(\mathrm{L}^{*}=48.5, \mathrm{a}^{*}=-16.4\right.$, and $\left.\mathrm{b}^{*}=26.2\right)$ with slightly darker green stripes $\left(\mathrm{L}^{*}=39.5, \mathrm{a}^{*}=\right.$ -13.5 , and $b^{*}=18.6$ ). Fruit flesh is very firm 


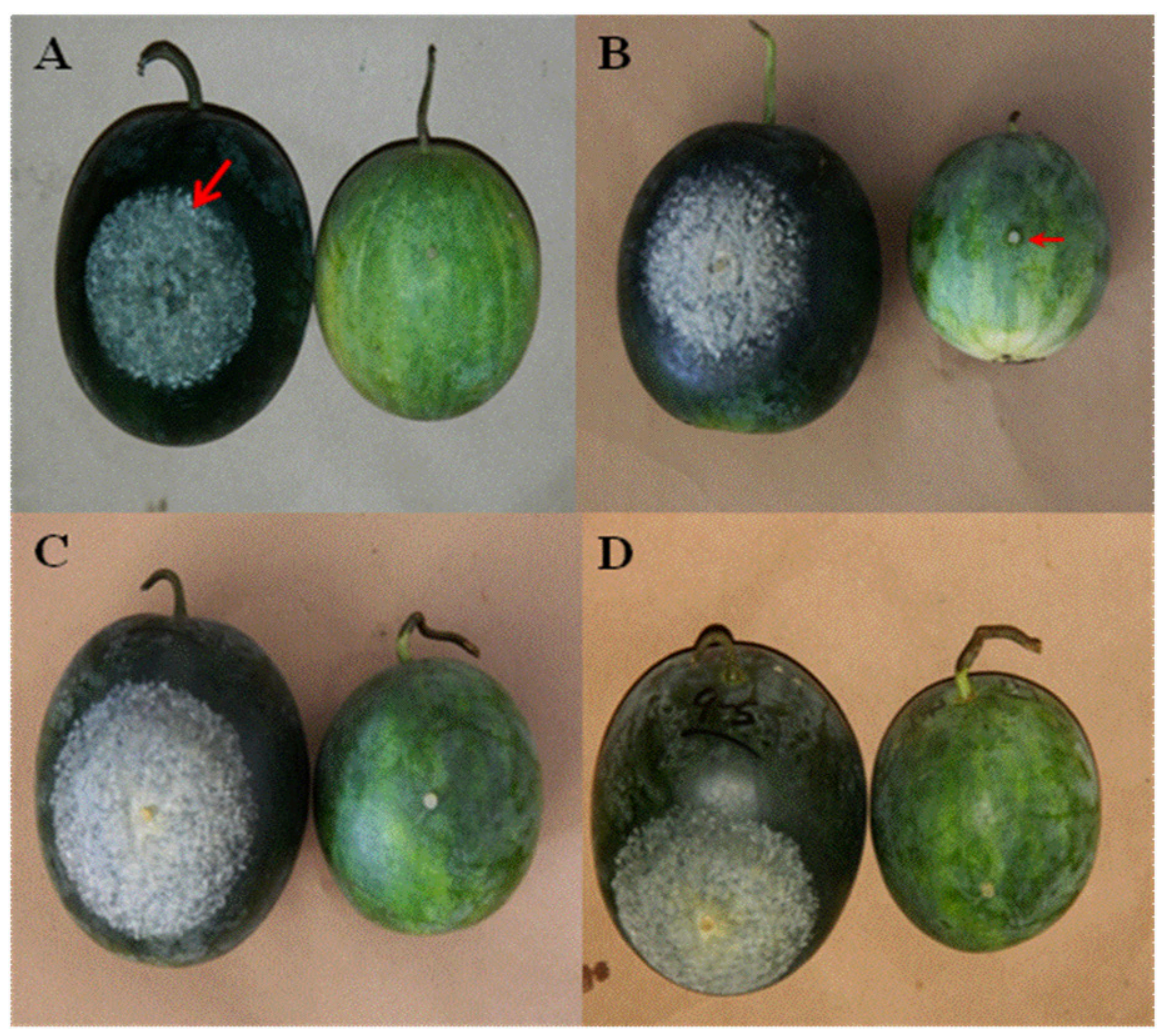

Fig. 1. Phytophthora fruit rot on susceptible commercial watermelon cultivars compared with resistant USVL germplasm lines. (A) Susceptible cultivar Sugar Baby (fruit on left) compared with resistant germplasm line USVL203-PFR (fruit on right). Intense sporulation (arrow) and growth of the fruit rot pathogen Phytophthora capsici is observed on susceptible cultivar Sugar Baby, whereas no sporulation is seen on USVL203-PFR and the three other USVL germplasm lines. (B) Cultivar Sugar Baby on left compared with USVL020-PFR on right. The red arrow shows a small lesion just surrounding the agar plug. These small lesions were generally dark black. (C) Susceptible cultivar Black Diamond on left compared with USVL489-PFR on right. (D) Susceptible cultivar Black Diamond on left compared with USVL782-PFR on right.

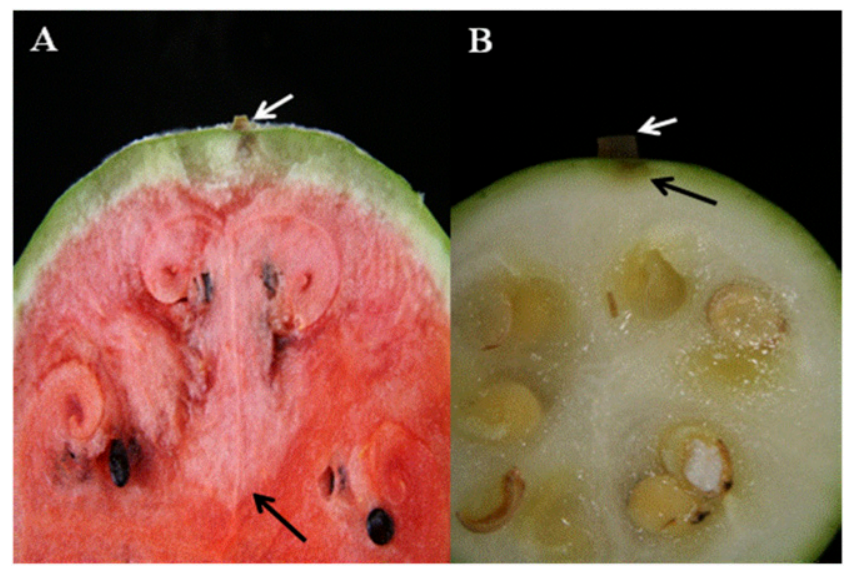

Fig. 2. Internal symptoms of Phytophthora fruit rot of watermelon. (A) Internal symptoms on the susceptible cultivar Mickey Lee. Symptoms and pathogen growth extend to the middle of the fruit of a susceptible cultivar (black arrow) $\mathrm{d}$ after inoculation with an agar plug (white arrow) from an isolate of Phytophthora capsici grown on V8 juice agar. (B) Internal symptom on resistant USVL germplasm line. Symptoms were generally expressed as a limited dark lesion on the rind (black arrow) on some fruits of the resistant lines. These lesions did not extend any further as observed on the susceptible cultivars.

and white-colored with medium-sized whitecolored egusi-type seeds. Each fruit generally weighs $\approx 1 \mathrm{~kg}$ (average, $1.03 \mathrm{~kg}$ ) in field tests conducted at Charleston, SC, and Fort Pierce, on trials conducted in 2012 and 2013 (Table 1; Fig. 1).

\section{Other Diseases}

The primary objective of this article is to report the release of four Phytophthora fruit rot-resistant watermelon germplasm lines. However, the original PIs used to develop USVL203-PFR, USVL020-PFR, and USVL489PFR have also been identified with resistance to other diseases (Davis et al., 2007; Gillaspie and Wright, 1993; Guner, 2004; Strange et al., 2002). The USVL PFR lines were also evaluated against several diseases in limited greenhouse trials to determine if these lines might still be resistant to some of the other reported diseases.

Zucchini yellow mosaic virus. PI 595203 that was used to develop USVL203-PFR was reported to have resistance to the aphid transmitted Zucchini yellow mosaic virus (ZYMV) (Guner, 2004). PI 595203 was developed by pure line selection in Georgia from WM-4 with resistance to WMV2 strain FC-1656 (<http://www.ars-grin.gov/cgi-bin/ npgs/acc/display.pl?1048740>). It was also resistant to isolates of WMV2 originating Arizona, California, and New York within the United States and from Israel and Italy. In greenhouse evaluations conducted in Charleston, SC, USVL203-PFR was resistant to ZYMV compared with the susceptible cultivars Mickey Lee and Charleston Gray. USVL782-PFR derived from PI 306782 (which is listed as resistant to WMV2 in GRIN) was more resistant than the susceptible cultivar Mickey Lee but was not as resistant as USVL203-PFR. Germplasm lines USVL020-PFR and USVL489-PFR were susceptible to ZYMV. These results were also confirmed by using a ZYMV-specific antibody in enzyme-linked immunosorbent assay (ELISA) tests (Kousik and Ling, unpublished results).

Papaya ringspot virus type W. PI 595203 was also reported resistant to Papaya ringspot virus (PRSV) (Strange et al., 2002). However, plants of the four USVL germplasm lines (USVL203-PFR, USVL020-PFR, and USVL489-PFR) were all susceptible to a Florida isolate of PRSV-W in greenhouse tests conducted in Fort Pierce, FL. Virus multiplication and high titers in these four germplasm lines were also confirmed by ELISA.

Powdery mildew. PI 560020 and PI 186489 used to develop USVL020-PFR and USVL489-PFR were reported to have moderate levels of resistance to powdery mildew (Davis et al., 2007). The cotyledons and hypocotyls of USVL020-PFR and USVL489PFR were moderately resistant to a melon race 1 strain of powdery mildew (Podosphaera xanthii) prevalent in our greenhouse when compared with susceptible PI 269677 and the cultivar Mickey Lee. However, USVL782PFR was not resistant to powdery mildew. Similarly, the true leaves of USVL203-PFR were observed to be susceptible to powdery mildew (Kousik, unpublished results). 


\section{Availability}

Small amounts of seeds of USVL489PFR, USVL782-PFR, USVL203-PFR, and USVL020-PFR produced by hand selfpollination in a greenhouse are available for distribution to interested research personnel and plant breeders. Address all requests to Shaker Kousik, USDA, ARS, U.S. Vegetable Laboratory, 2700 Savannah Highway, Charleston, SC 29414 (e-mail: shaker.kousik@ ars.usda.gov). Seeds of USVL489-PFR, USVL782-PFR USVL203-PFR, and USVL020PFR will also be submitted to the National Plant Germplasm System where they will be available to interested parties. It is requested that appropriate recognition of the source be given when this germplasm contributes to research or development of a new breeding line or cultivar.

\section{Literature Cited}

Davis, A.R., A. Levi, A. Tetteh, T.C. Wehner, and M. Pitrat. 2007. Evaluation of watermelon and related species for resistance to race $1 \mathrm{~W}$ powdery mildew. J. Amer. Soc. Hort. Sci. 132:790795.

Gevens, A.J., P.D. Roberts, R.J. McGovern, and T.A. Kucharek. 2008. Vegetable diseases caused by Phytophthora capsici in Florida University of Florida, Extension Digital Information Source SP159. <http://edis.ifas.ufl. edu/vh045>.

Gillaspie, A.G. and J.M. Wright. 1993. Evaluation of Citrullus sp. germplasm for resistance to Watermelon mosaic virus 2. Plant Dis. 77:352-354.

Glosier, B.R., E.A. Ogundiwin, G.S. Sidhu, D.R Sischo, and J.R. Prince. 2008. A differential series of pepper (Capsicum annuиm) lines delineates fourteen physiological races of Phytophthora capsici. Euphytica 162:23-30.

Granke, L.L., L.M. Quesada-Ocampo, and M.K. Hausbeck. 2011. Differences in virulence of Phytophthora capsici isolates from a worldwide collection on host fruits. Eur. J. Plant Pathol. 132:281-296.

Granke, L.L., L.M. Quesada-Ocampo, K. Lamour, and M.K. Hausbeck. 2012. Advances in research on Phytophthora capsici on vegetable crops in the United States. Plant Dis. 96:15881600.

Guner, N. 2004. Papaya ring spot virus watermelon strain and Zucchini yellow mosaic virus resistance in watermelon. PhD diss., Dept. Hort. Sci., North Carolina State Univ., Raleigh, NC.

Hausbeck, M.K. and K.H. Lamour. 2004. Phytophthora capsici on vegetable crops: Research progress and management challenges. Plant Dis. 88:1292-1303.

Jester, W. and G.J. Holmes. 2003. Phytophthora fruit rot-A menace to watermelon production.
$<$ http://www.nationalwatermelonassociation com/scientific_phytophthorafruitrot.php $>$.

Kousik, C.S., M.L. Adams, W.R. Jester, R. Hassell, H.F. Harrison, and G.J. Holmes. 2011. Effect of cultural practices and fungicides on Phytophthora fruit rot of watermelon in the Carolinas. Crop Prot. 30:888-894.

Kousik, C.S., J. Ikerd, W.P. Wechter, H. Harrison, and A. Levi. 2012. Resistance to Phytophthora fruit rot of watermelon caused by Phytophthora capsici in U.S. Plant Introductions. HortScience 47:1682-1689.

McGrath, M.T. 1996. Phytophthora fruit rot, p. 5354. In: Zitter, T.A., D.L. Hopkins, and C.E. Thomas (eds.). Compendium of cucurbit diseases. APS Press, St. Paul, MN.

Morrissey, B. 2006. NWA update. The vineline. April 2006 issue. p. 7-10.

Quesada-Ocampo, L.M., L.L. Granke, and M.K. Hausbeck. 2010. Differences in virulence of Phytophthora capsici isolates from a worldwide collection on zucchini fruits, p. 248-251. In: Thies, J.A., C.S. Kousik, and A. Levi (eds.). Proc. of Cucurbitaceae 2010. American Society of Horticultural Science, Alexandria, VA.

Strange, B.E., N. Guner, Z. Pesic-VanEsbroeck, and T.C. Wehner. 2002. Screening the watermelon germplasm collection for resistance to Papaya ring spot virus type-W. Crop Sci. 42:1324-1330.

Wiant, J.S. and C.M. Tucker. 1940. A rot of winter queen watermelon caused by Phytophthora capsici. J. Agr. Res. 60:73-88. 